\title{
OVERMODED, HIGH-POWER 0.2 THZ RADIATION SOURCE BASED ON A CYLINDRICAL 2D PERIODIC SURFACE LATTICE CAVITY*
}

\author{
Amy J. MacLachlan, Craig W. Robertson, Adrian W. Cross, \\ Kevin Ronald and Alan D. R. Phelps \\ Department of Physics, SUPA, University of Strathclyde, \\ Glasgow, G4 ONG, Scotland, UK
}

We present the theoretical and numerical study of a cylindrical two-dimensional periodic surface lattice (2D PSL) overmoded interaction cavity, excited by a thin, annular electron beam, immersed in a magnetic field. This high-power $0.2 \mathrm{THz}$ radiation source with applications in plasma diagnostics, imaging, spectroscopy, radar, and communications is designed and simulated using the PIC solver of CST Microwave Studio. The amplitude of the corrugation is sufficiently small that the 2D PSL can be described as an effective metadielectric ${ }^{1}$. Coupling of volume and surface modes occurs ${ }^{2-6}$ when optimum parameters and dimensions are chosen. The energy of the electron beam and the periodicities of the PSL are chosen for effective electron beam coupling. We demonstrate the production of well-defined, high-power $0.2 \mathrm{THz}$ radiation.

1. I. V. Konoplev, A. J. MacLachlan, C. W. Robertson, et al., "Cylindrical periodic surface lattice as a metadielectric: concept of a surface-field Cherenkov source of coherent radiation", Phys. Rev. A, vol. 84, 013836, 2011.

2. A. J. MacLachlan, C.W. Robertson, A.W. Cross, et al., "Volume and surface mode coupling experiments in periodic surface structures for use in $\mathrm{mm}-\mathrm{THz}$ high power radiation sources", AIP Advances, vol. 8, 105115, 2018.

3. A. J. MacLachlan, C. W. Robertson, I. V. Konoplev, et al., "Resonant excitation of volume and surface fields on complex electrodynamic surfaces", Phys. Rev. Appl., vol. 11, 034034, 2019.

4. A. J. MacLachlan, C. W. Robertson, K. Ronald, et al., "Mode coupling in periodic surface lattice and metamaterial structures for mm-wave and THz applications", SN Applied Sciences., vol. 1, 613, 2019.

5. A. J. MacLachlan, C. W. Robertson, A. W. Cross, et al.,, IET Microwaves, Antennas \& Propagation, vol. 14, (11), 1151 $-1156,2020$.

6. N. S. Ginzburg, E. V. Ilyakov, I. S. Kulagin, et al., Phys. Rev. Accel. and Beams, vol. 21, 080701, 2018.

\footnotetext{
* Work supported by AFOSR award numbers FA8655-13-12132 and FA9550-17-1-0095
} 